\title{
Identification of the knowledge conflicts' sources in the architecture of cognitive agents supporting decision-making process
}

\author{
Jadwiga Sobieska-Karpińska \\ Wrocław University of Economics \\ ul. Komandorska 118/120, \\ 53-345 Wrocław, Poland \\ Email: jadwiga.sobieska-karpinska@ue.wroc.pl
}

\author{
Marcin Hernes \\ Wrocław University of Economics \\ ul. Komandorska 118/120, \\ 53-345 Wrocław, Poland \\ Email: marcin.hernes@ue.wroc.pl
}

\begin{abstract}
This article presents the problem of knowledge conflicts identification in the architecture of cognitive agents. The agents operate at the decision support systems. The types and the sample of cognitive agents architecture was characterized in the first part of article. Next, the causes of knowledge conflicts was indicated. The final part of article contains the analysis of sources of knowledge conflicts and their examples related to decision-making process.
\end{abstract}

\section{INTRODUCTION}

A DECISION-MAKING process may be supported by the use of tools of various kind, in particular IT systems. Currently used IT tools (systems) support decisionmaking mainly at an operational and tactical level but they become insufficient at a strategic level. They only enable the analysis of the form of information, the links between economic values and they are unable to analyse their meaning. Thus these tools mainly serve the conversion of the gathered data (mostly disordered and unstructured) into information useful, legible and easily interpretable and thus more suitable to a decision-maker. However, for the definition of meaning of information, a human mind is necessary, and the change of knowledge into wisdom (necessary to take a good decision) - requires not only human intellect but even human genius [19]. Therefore, it seems justified to use the tools which perform cognitive and decision-making functions, the ones that take place in the human brain and owing to this are capable of understanding the real meaning of the observed phenomena and economic processes taking place in the organization environment. These tools include cognitive agents which often cooperate within the framework of a multi-agent system [e.g. 21] in order to effectively reach a set goal.

The architectures of cognitive agents are complex and their functioning is of asynchronous nature, which may be the reason for the occurrence of knowledge conflicts and have a negative impact on the results of cognitive and decision-making functions, which in turn may hinder supporting a decision-making process.

Previous research related to the issues of knowledge conflicts, and in particular with defining their sources [e.g. 10, 20] relate mostly to multi-agent systems composed of reactive agents, so the ones which are capable of drawing conclusions and adequately react to stimuli from the environ- ment however do not have the cognitive function and have limited learning skills. With respect to the agents of this kind, knowledge conflicts occur in situations of opposition or in-coherence of the knowledge held by the agent $[7,14$, $15,18]$. However, works concerning the sources of knowledge conflicts with respect to cognitive agent [e.g. 12, 16] are limited to very general approaches, and they do not take into consideration modules of agent's architecture. This may result from the fact that the implementation of various architectures of cognitive agents is currently mainly at a prototype stage and few of them function in commercial solutions and thus the problem of occurrence of knowledge conflicts is not raised. The work [13], for example, presents using intelligent technologies, such as Bayesian Network CaseBased Reasoning, Expert System, Fuzzy System, Genetic Algorithms and Ontology Based techniques for resolving different types of conflicts both reactive and cognitive agents, however they are not related to agents architecture. The work [3] presents cognitive agents resolving methods only on the development stage (design time, programming), the knowledge conflicts at the runtime are not taking into consideration.

However, more intensive development of cognitive agent is noticeable, which may lead to a situation in which the knowledge of these agents will be so extensive that the issue of defining the sources of knowledge conflicts as well as the methods of their solving will become very significant both from a theoretical point of view and from the point of view of persons dealing with designing cognitive agents and multi-agent systems made of them. An automatic solution to the knowledge conflict, as stated in the study [8], is a key element of the functioning of multi-agent systems.

Thus the purpose of this article is to analyse the sources of knowledge conflicts occurring in the architecture of cognitive agent supporting a decision-making process.

\section{The Modules Of Cognitive Agent's ArChitecture As A Potential Places Of KNOWLEdge Conflicts SOURCES}

The most important features of all cognitive agents' architectures include the way of their memory organization and learning mechanisms. The memory is the repository of the knowledge about the world and oneself, the objectives and 
current actions. The role of memory is understood differently by the authors $[5,6,8,9,12]$. The organization of the memory depends on the manner of knowledge representation. Learning is a process which transforms the remembered knowledge and the manner of its use. In the study [4] considering the taxonomy of cognitive agent architectures with respect to two above mentioned features, three main groups of the architectures were distinguished:

1. Symbolic architectures which use declarative knowledge included in relations recorded at the symbolic level, focusing on the use of this knowledge to solve problems. This group of architectures includes, among others: State, Operator And Result (SOAR), Executive Process Interactive Control (EPIC), Semantic Network Processing System (SNePS), CopyCat, Non-Axiomatic Reasoning System (NARS), Integrated Cognitive-Neuroscience Architectures for Understanding Sensemaking (ICARUS).

2. Emergent architectures using signal flows through the network of numerous, mutually interacting elements, in which emergent conditions occur, possible to be interpreted in a symbolic way. This group of architectures includes, among others: Neurally Organized Mobile Adaptive Device (NOMAD), Numenta Platform for Intelligent Computing (NuPIC) Cortronics, Brain-Emulating Cognition and Control Architecture (BECCA).

3. Hybrid architectures which are the combinations of the symbolic and emergent approach, combined in various ways. This group of architectures includes, among others: Adaptive Components of Thought-Rational (ACTR), The Connectionist Learning Adaptive Rule Induction ON-line (CLARION), CogPrime, DUAL, Cortical Capacity-Constrained Concurrent Activation-based Production System (4CAPS), The Novamente AI Engine, Cognitive Agents Architecture (Cougaar), The Learning Intelligent Distribution Agent (LIDA).

It was decided to analyse in this article (due to its volume), with respect to the sources of knowledge conflicts, only the architectures of the LIDA cognitive agent, proposed by S. Franklin [11], presented in the Fig 1. This architecture is of emergent-symbolic nature, owing to which the processing of both structured (numerical and symbolic) knowledge and unstructured (recorded in the natural language) is possible. In addition, the Cognitive Computing Research Group established by S. Franklin, elaborated in 2011 the framework (in Java language) significantly facilitating the implementation of the cognitive agent. It should also be emphasized that the whole framework code is open, i.e. the developer has access to the definitions of all methods, as opposed to, for instance, Cougaar architecture framework software, in which the agent's software code constitutes the so-called "blackbox".

In the LIDA architecture, presented on Fig 1, it was adopted that the majority of basic operations are performed by the so-called codelets, namely specialized, mobile programmes processing in-formation in the model of global workspace. The functioning of the cognitive agent is performed within the framework of the cognitive cycle and it is divided into three phases: the understanding phase, the consciousness phase and the selection of actions and learning phase. At the beginning of the understanding phase the stimuli received from the environment activate the codelets of the low level features in the sensory memory [11]. The outlets of these codelets activate the perceptual memory, where high level feature codelets supply more abstract things such as objects, categories, actions or events. The perception results are transferred to workspace and on the basis of episodic and declarative memory local links are created and then, with the use of the occurrences of perceptual memory, a current situational model is generated; it other words the agent understands what phenomena are occurring in the environment of the organization. The consciousness phase starts with forming of the coalition of the most significant elements of the situational model, which then compete for attention so the place in the workspace, by using attentional codelets. The contents of the workspace module is then transferred to the global workspace (the so-called "broadcasting" is taking place), simultaneously initializing the phase of action selection. At this phase possible action schemes are taken from procedural memory and sent to the action selection module, where there compete for the selection in a given cycle. The selected actions activate sensorymotor memory for the purpose of creating an appropriate algorithm of their performance, which is the final stage of the cognitive cycle [1]. The cognitive cycle is repeated with the frequency of 5 - 10 times per second.

Parallelly with the previous actions the agent's learning is performed (Fig 1), which is divided into perceptual learning concerning the recognition of new objects, categories, relations; episodic learning which means remembering specific events: what, where, when, occurring in the working memory and thus available in the awareness; procedural learning, namely learning new actions and action sequences needed for solving the problems set; conscious learning relates to learning new, conscious behaviours or strengthening the existing conscious behaviours, which occurs when a given element of the situational model is often in the workspace. The agent's learning may be performed as learning with or without a teacher.

It is worth emphasizing that each cognitive agent supporting decision-making must have the ability of grounding the symbols, namely assign relevant real world objects to specific symbols of the natural language. This is necessary to correctly process unstructured knowledge saved mainly by means of the natural language and thus, for instance, the clients' opinions on products. The knowledge of this type is currently becoming more and more significant for a company because it may have impact on its competitiveness level. For instance analysing the clients' opinions on a given product, the sales volume of a given product in the future may be estimated (of course with a certain level of probability).

Taking into consideration:

- the complexity of the cognitive agent's architecture (Fig 1) and functionality, 

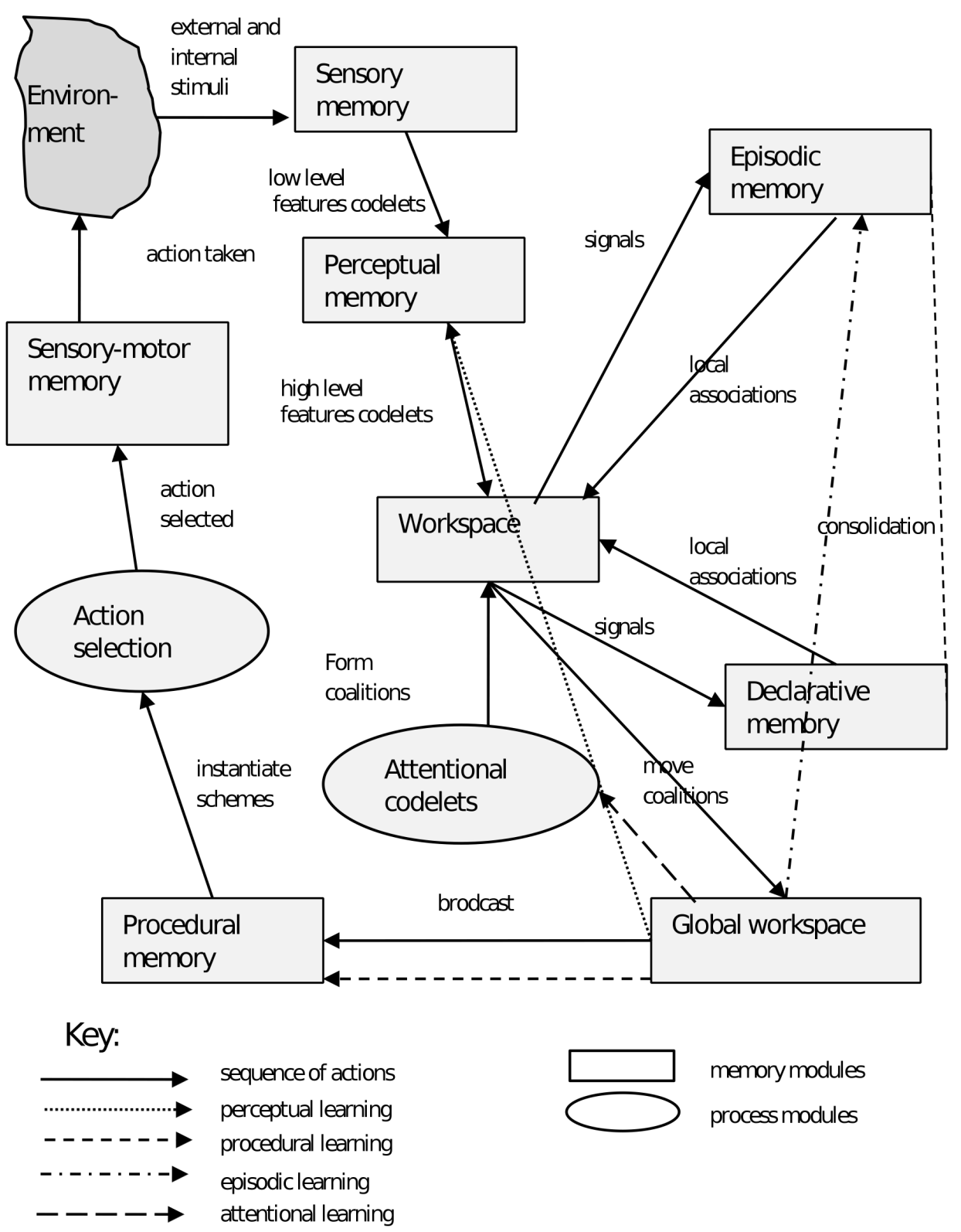

Fig. 1 The architecture of LIDA cognitive agent. Source: Own work on the basis of $[1,2]$

- asynchronous nature of the cognitive cycle (5-10 cycles per second) having impact on the contents of particular architecture models,

it may be concluded that they may constitute the reasons for the occurrence of knowledge conflicts. Potential places of these conflicts' sources may occur in the modules of the cognitive agent's architecture and be connected with:

- the domain of the value of objects stored in memory,

- the results of phenomena interpretation,

- events,

- rules,
- the perception of the current state of the environment (objects and links between them),

- the results of algorithm operation,

- the selection of the agent's actions.

Further in the article the sources of knowledge conflicts will be presented, illustrated with specific examples, connected with supporting the company decision-making process. 


\section{Sources of KNOWLEDGE CONFLICTS CONNECTED} With Supporting The Decision-Making Process

The environment of the functioning of cognitive agents supporting decision-making process, constitutes the company and its environment. The occurrence of knowledge conflicts is related to a situation when various values are assigned to the same objects, links between them, features, phenomena events and actions occurring in the environment of the party to a conflict. Generating various decisions by agents, at the same time, may serve as an example [17].

For the needs of considerations made in the article, the sources of the conflicts of knowledge will be presented at the example of an agent, the objective of which is customer relation management. This agent constantly obtains stimuli from the environment which relate to the characteristics of sales such as sales dynamics indexes in break-up into particular clients (delivered for instance from the agent/agents supporting logistic processes), the clients' opinions of products (being for instance in the company on-line store database), characteristics of products offered by the competition, actions taken by the competition (delivered for instance by the agent monitoring competition). The further part of article describes modules of agent's architecture from the point of view of the occurrence of conflicts of knowledge.

\section{A. Sensory memory}

As sales characteristics are stored, on regular basis, in the agent's sensor memory, the contents of this memory may constitute the source of knowledge conflict. These conflicts are mainly connected with the domain of the value of objects stored in the memory. For instance, if it was adopted in the solution that the memory should include the users' opinions recorded in the text form, however there occurs a situation in which the opinion contains graphic elements, their interpretation may be difficult or even impossible. As a consequence, the cognitive agent may incorrectly perceive the current state of the environment.

\section{B. Perceptual memory}

Sales characteristics are sent further to the perceptual memory where they are interpreted, for instance determining whether the clients' opinions are positive or negative or determining the difference between the characteristics of products offered by the company in question and the characteristics of products offered by the competition. The knowledge conflicts occurring in the perceptive memory are thus connected with the results of its contents interpretation. For example, if an opinion contains only the product characteristics such as the color, dimensions, the function, it is difficult to determine the polarity of the opinion (state whether the opinion is positive or negative).

\section{Workspace, episodic memory and declarative memory}

The perception results in the form of objects or events are sent to the workspace in which knowledge conflicts relate to the perception of the current state of the environment and are connected with the creation of local links with the use of events stored in the episodic memory and the rules stored in the declarative memory. Knowledge conflicts connected with the contents of episodic memory mainly relate to contradictory events which occurred as a result of the earlier event. For example, the earlier event recorded in the episodic memory is: "two years before the competition launched two products (which are also manufactured by the company in question) with better characteristics (product 1 and product 2) and later events recorded in the episodic memory include: "in the previous year the sales of product 1 decreased" and "in the previous year the sales of product 2 increased)" The knowledge conflicts occurring in the declarative memory are connected with the occurrence of the contradiction of rules (for instance "if the users' opinions are negative, the decrease in sales will take place", and "if users' opinions are negative, the sales will remain at the same level").

Based on episodic and declarative memory a current situational model is generated, in the workspace, in the form of objects (for example sales characteristics), events (for example the actions of the competition) and links among them (for example: the competition offered a product with better characteristics and in our company a decrease in sales is observed"). Knowledge conflicts occurring in the workspace take place as a result of conflicts occurring in the episodic and declarative memory - the current situational model may contain incorrect objects or incorrect links between them.

\section{Attentional codelets}

In the attentional codelets module, there are significant elements of the situational model (the agent "rejects" insignificant elements of the situational model such as for instance "the drop of sales of products to the client X occurred because this client liquidated business" - this element is insignificant as no marketing actions can be taken with respect to client $\mathrm{X}$ any more). The conflict of knowledge in this module relates to the results of algorithm actions determining which elements of the current situational model are insignificant.

\section{E. Procedural memory}

The procedural memory, in turn, contains specific action schemes - for instance "improving the product characteristics", "lowering the product price", "launching the new product meeting the clients' expectations on the market". The conflict of knowledge relates to algorithms implemented as an action scheme, for instance determining what measures should be taken to launch a new product on the market.

\section{F. Action selection module}

The knowledge conflict in the action selection module relates to decisions which should be taken, for instance whether the action: "lowering the product price" or "launching a new product meeting the clients' expectations" should be chosen.

\section{G. Global workspace and sensory-motor memory}

In the cognitive agent's architecture there are also modules in which the sources of knowledge conflicts do not oc- 
cur. They include: the global workspace (sources of knowledge conflicts do not occur in this module because there are significant elements of the situational model transferred from the module of current awareness for the purpose of initiating the phase of action selection) and sensory-motor memory (the sources of knowledge conflicts do not occur in this memory because it is a working module).

\section{H. Discussion}

It should be noticed that the occurrence of the conflict results in restrictions in the agent's learning process. For instance, implementing perceptual learning, the agent may learn the interpretation of unknown economic indexes (for instance looking for their interpretation on the Internet learning without a teacher or using human assistance - learning with a teacher). If, however, the index interpretations found are contradictory, the process of perceptive learning is disturbed.

And implementing procedural learning (learning without a teacher may be applied here as well (the agent may use the actions defined in its own perceptive memory and assigned so far to other elements of the situational model), with a critic (for example the agent may assign particular actions implemented in connection with the decrease in the sales dynamics and a person defines whether the actions are correct) or with a teacher, (the agent may for instance learn what actions should be taken in a situation when sales is dropping in a company and the competition is launching a new product). If the action algorithms are different (a knowledge conflict occurs), the learning process will be disturbed as well.

Knowledge conflicts occurring in the episodic memory have, in turn, a negative impact on episodic learning (performed without a teacher) consisting in remembering all events occurring in the environment.

Conscious learning (performed without a teacher), on the other hand, consisting in determining which elements of a situational model are significant, may be limited by knowledge conflicts occurring both in the workspace and in the attentional codelets module.

It should be also emphasized that the sources of knowledge conflicts may occur in other symbolic, emergent and hybrid architectures of cognitive agents. As similarly as LIDA architecture, their structure consists of many modules.

\section{CONCLUSION}

The use of cognitive agent for the purpose of supporting decision-making allows for the implementation of actions performed in a company by a human being so far, starting with the operation of work stations, through the diagnosis of the current economic situation to automatic decision-taking, both at the operational, tactical and strategic level. This is connected with the agents' skills in the scope of correct interpretation and associating of facts, discovering links between the objects and phenomena of the real world, learning and having experience.

For cognitive agent to be able to effectively perform their tasks, they should be created upon conducting the analysis of particular modules, with respect to knowledge conflicts.
Thus the identification of the sources of knowledge conflicts, presented in the article, and its consideration at designing the decision-making process support systems will allow for automatic detection of conflicts of this kind and, as a consequence, their solving. These actions are extremely significant because, as has already been emphasized, they have a positive influence on the effectiveness of processes performed by an agent, and, in turn, the effectiveness of decisions taking place in a company.

This results in the need to perform further research works connected with, among others, the elaboration of the formal model of conflict solving and the creation of the prototype of cognitive decision-support system.

\section{REFERENCES}

[1] A. Bytniewski, Hernes M., ,Wykorzystanie agentów kognitywnych w budowie zintegrowanego systemu informatycznego zarządzania”, in: T. Porębska-Miąc, H. Sroka (ed.), Systemy Wspomagania Organizacji, Wydawnictwo Uniwersytetu Ekonomicznego w Katowicach, Katowice 2013.

[2] Cognitive Computing Research Group, http://ccrg.cs.memphis.edu/, access date: 29.01.2014.

[3] M. Dastani , G. Governatori , A. Rotolo , L. Van Der Torre, "Programming cognitive agents in defeasible logic", LPAR 2005, DOI: 10.1.1.76.6973.

[4] W. Duch, Architektury kognitywne, czyli jak zbudować sztuczny umysł, in: R. Tadeusiewicz (ed.) Neurocybernetyka teoretyczna, Wydawnictwa Uniwersytetu Warszawskiego, Warszawa 2010.

[5] J. Hawkins, S. Blakeslee, "On intelligence: How a New Understanding of the Brain will Lead to the Creation of Truly Intelligent Machines", Times Books 2004

[6] R. Hecht-Nielsen, "Confabulation Theory: The Mechanism of Thought", Springer 2007.

[7] M. Hernes, N.T Nguyen, "Deriving Consensus for Hierarchical Incomplete Ordered Partitions and Coverings", Journal of Universal Computer Science, no. 13(2), pp. 317-328, 2007.

[8] M. Hernes M, J. Sobieska-Karpińska, "A comparative analysis of conflicts resolving methods in multiagent decision support systems", in: M. Pańkowska, H. Sroka, S. Stanek (ed.), Cognition and creativity support systems, Studia Ekonomiczne. Zeszyty Naukowe Wydziałowe UE w Katowicach, Wydawnictwo UE w Katowicach, Katowice 2013, s. 23-32.

[9] M. Dastani, L. Van der Torre, "A Classification of Cognitive Agents", in: W.D. Gray, C.D. Schun (ed.), Proceedings of the Twenty-Fourth Annual Conference of the Cognitive Science Society, Cognitive Science Society, Mahwah 2002. DOI: 10.1.1.16.8401.

[10] D. De Long, P. Seemann, “ Confronting Conceptual Confusion and Conflict in Knowledge Management", Organizational Dynamics, 2000.

[11] S. Franklin, F.G. Patterson, "The LIDA architecture: Adding new modes of learning to an intelligent, autonomous, software agent". in: Proc. of the Int. Conf. on Integrated Design and Process Technology. San Diego, CA: Society for Design and Process Science, 2006.

[12] A. Hensinger, M. Thome, T. Wright, "Cougaar: A Scalable, Distributed Multi-Agent Architecture", IEEE International Conference on Systems, Man and Cybernetics, 2004. DOI: 10.1109/ICSMC.2004.1399959.

[13] K.M. Khalil, M. Abdel-Aziz, T. T. Nazmy T, A. M. Salem, "Intelligent Techniques for Resolving Conflicts of Knowledge in Multi-Agent Decision Support Systems", Sixth International Conference on Intelligence Computing and Information Systems, Cairo, Egypt, 2013, DOI: arXiv: 1401.4381 .

[14] W. Lorkiewicz, "An approach to resolving semantic conflicts of temporally-vague observations in artificial cognitive agent", Proceedings of the 10th international conference on Knowledge-Based Intelligent Information and Engineering Systems - Volume Part III, Springer-Verlag 2006 pp. 1004-1011. DOI: 10.1007/11893011_127.

[15] B. Mianowska, N. T. Nguyen, "Using knowledge integration techniques for user profile adaptation method in document retrieval systems", Transactions on computational collective intelligence V, Springer-Verlag Berlin, Heidelberg, 2011. 
[16] NT. Nguyen, R. Katarzyniak, "Multi-agent Systems, Ontologies and Conflict Resolution". Special issue in Journal of Intelligent \& Fuzzy Systems 17(3), 2006.

[17] J. Sobieska-Karpińska, M. Hernes, "Consensus determining algorithm in multiagent decision support system with taking into consideration improving agent's knowledge", Federated Conference Computer Science and Information Systems (FedCSIS), 2012.

[18] J. Sobieska-Karpińska, M. Hernes, "The postulates of consensus determining in financial decision support systems", in: Annals of Computer Science and Information Systems, Proceedings of Federated Conference Computer Science and Information Systems (FedCSIS) Kraków, 2013, ISSN 2300-5963, s. 1165 - 1168.
[19] R. Tadeusiewicz, , Systemy kognitywne - nowy wymiar informatyki ekonomicznej”, http://ryszardtadeusiewicz.natemat.pl/75001,systemykognitywne-nowy-wymiar-informatyki-ekonomicznej [29.12.2013].

[20] R. Yager., “Approximate reasoning and conflict resolution”, Machine Intelligence Institute, Iona College, 2000.

[21] M. Żytniewski, R. Kowal, A. Sołtysik, "The outcomes of the research in areas of application and impact of software agents societies to organizations so far. Examples of implementation in Polish companies", in: Annals of Computer Science and Information Systems, Proceedings of Federated Conference Computer Science and Information Systems (FedCSIS), Kraków, 2013 s. 1165 - 1168 